\title{
PERFORMANCE CHARACTERISTICS OF FIBER MODIFIED ASPHALT CONCRETE MIXES
}

\author{
Manoj Shukla, Senior Scientist, Central Road Research Institute (CRRI), New Delhi, India. Email: \\ manoj.crri@nic.in \\ Dr. Devesh Tiwari, Principal Scientist, Central Road Research Institute (CRRI), New Delhi, India. \\ Email: devesht.crri@nic.in \\ K. Sitaramanjaneyulu, Senior Principal Scientist, Central Road Research Institute (CRRI), New Delhi, \\ India.Email: Ksitaramcrri@yahoo.co.in
}

doi: 10.2478/ijpeat-2013-0007

\begin{abstract}
Asphalt binder modification is one of the approaches taken to improve pavement performance. In addition it may also be improved through the addition of fibers to Asphalt mix that enhances material strength and fatigue characteristics while adding ductility. Due to their inherent compatibility with Asphalt concrete and excellent mechanical properties, fibers offer an excellent potential for modification of Asphalt concrete mix. To investigate the behavior of Fiber Modified Asphalt Concrete Mixes (FMACM), a preliminary study has been done to determine the feasibility of modifying the behavior of a Asphalt Concrete (AC) mixture through the use of Glass fiber and Polyester fiber. The purpose of this study was to identify and understand the factor that is responsible for improving the behavior of FMACM. Asphalt concrete samples were prepared and tested in the laboratory to evaluate the various mixture characteristics. The conclusions drawn from the study on testing of fiber-modified mixes are that fiber modified Asphalt mixtures have shown increased stiffness and resistance to permanent deformation. Fatigue characteristics of the mixtures were also improved. Fibers used in the study were of high tensile strength therefore test results of FMACM have shown higher indirect tensile strength and improved skid resistance for paving applications.
\end{abstract}

KEY WORDS: Glass fiber, Polyester fiber, flexure fatigue test, cracking, permanent deformation, indirect tensile strength

\section{INTRODUCTION}

Modification of Asphalt Concrete Mix can be done in many ways such as modification of binder through polymers, crumb rubber etc. or reinforcing of AC mixes. Fiber reinforcement was used as a crack barrier rather than a reinforcing element whose function is to carry the tensile loads as well as to prevent the formation and propagation of cracks. Thin fibers exhibit much higher rupture stresses than the same in thicker form. The strengthening mechanism operates because the glass fiber carries the applied stress over a high tenacity cross-section and distributes it to the weaker material as a shearing stress over a relatively long periphery. Synthetic fibers provide a different mode for extending the life of overlays. They re-distribute the strain in an overlay immediately above a crack reflecting upward. Glass fibers are more effective against bending and thermal contraction displacement than against shear displacement. In the present study laboratory test involved are beam fatigue test, 
indirect tensile tests, repeated load creep and permanent deformation tests, besides all other common tests such as density, Marshall Stability, moisture susceptibility, and others. This study investigates on the characteristics and properties of FMACM, which may have the benefit for improving the performance of pavement.

\subsection{Literature Review on Fibers Modified Asphalt Mixes}

The cellulose fibers are currently being used extensively in porous asphalt friction course, with the primary purpose of increasing asphalt content without any drain down problem (Busching et al. 1968). The fiber reinforces the binder system, thus causing an increase in the viscosity of the system. The resulting mix has greater stability and possibly higher resistance to fatigue cracking than similar mixes without addition of fibers. The mineral fibers are typically heavier than the cellulose fibers and therefore is used at a higher content by weight in mixture so that sufficient volume of fibers is available.

Serfass et al. (1966) examined the effects of fiber modified asphalt utilizing asbestos, rock wool, glass wool, and cellulose fibers and concluded that adding fibers enables developing mixtures rich in asphalt and therefore displaying high resistance to moisture, aging, fatigue, and cracking. Simpson et al. (1984) conducted a study of modified asphalt mixtures in Somerset, Kentucky. Polypropylene, polyester fibers and Crumb Rubbers were used to modify the asphalt binder. Two proprietary blends of modified binder were also evaluated. An unmodified mixture was used as a control. Mixtures containing polypropylene fibers were found to have higher tensile strengths and resistance to cracking. Rutting potential as measured by repeated load deformation testing was found to decrease in modified samples. The suitability of a mineral fiber for use in road asphalt is thus dependent on two criteria i.e. average fiber diameter and average fiber length. Though both fibers are not similar in shape (cross section) but the length are almost similar. Therefore, the laboratory performances have been compared with respect to different tests.

The use of Glass fiber showed consistent results (Abdelaziz et al. 2005) and it was found that the addition of fiber does affect the properties of asphalt mixes, by decreasing its stability and an increase in the flow value as well as the voids in the mix. The results indicated that the fiber has the potential to resist structural distress that occur in road pavement as result of increased traffic loading, thus improving fatigue life by increasing the resistance to cracking and permanent deformation. On the whole, the results showed that the addition of glass fiber will be beneficial in improving some of the main properties of the flexible pavement. Praveen et al. (2009) has reported that the indirect tensile strength increases with an increase in fibers content in the mix. The tensile strength ratio and retained stability increase with an increase in fibers content, indicating improved moisture resistance. Permanent deformation decreases with an increase in fibers content, indicating a decrease in rutting potential. Decoene, Y (1990) have concluded that use of cellulose fibers is suitable for porous Asphalt mixes. Jiang et.al (1993) and Maurer, et al. (1989) emphasised on use of fibers to retard reflective cracking in pavements. 


\section{ASPHALT CONCRETE MIXTURE CHARACTERIZATION}

\subsection{Material}

For the laboratory study, Delhi Quartzite aggregate of sizes $20 \mathrm{~mm}, 10 \mathrm{~mm}$, stone dust and lime were used and tested as per IS Standards. Asphalt of Viscosity Grade-30 (VG-30) was used and tested as per Bureau of Indian Standards (BIS) (1978). The results of tests performed on asphalt for the study are shown in Table 1 and basic tests on aggregates performed during the study are shown in Table 2 as per BIS (1978) and limits as per the specifications of Ministry of Road Transport and Highways (MoRTH) (2001). The asphalt mix design was done on a control gradation of Asphalt Concrete (AC) mixture as per MoRTH (2001) which is shown in Fig-1. The MoRTH specification also states that either of one test is needed i.e. Aggregate Impact Value test or Los Angeles Abrasion test, therefore in the present research only Aggregate Impact Value test has been done.

Table 1. Test results of asphalt

\begin{tabular}{|c|l|c|}
\hline $\begin{array}{c}\text { Sr. } \\
\text { no. }\end{array}$ & Test description & Results \\
\hline 1. & Penetration at $25^{\circ} \mathrm{C}, 100 \mathrm{~g}, 5 \mathrm{~s}$. & $7 \mathrm{~mm}$ \\
\hline 2. & Ductility at $27^{\circ} \mathrm{C}$ & $98 \mathrm{~cm}$ \\
\hline 3. & Specific Gravity & $1.01-$ \\
\hline 4. & Softening Point & $49^{\circ} \mathrm{C}$ \\
\hline 5. & Flash Point & $285^{\circ} \mathrm{C}$ \\
& Fire Point & $296^{\circ} \mathrm{C}$ \\
\hline 6. & Viscosity(Pa s) at $135^{\circ} \mathrm{C}$ & 5.4 \\
\hline
\end{tabular}

Table 2. Test results of aggregates

\begin{tabular}{|l|l|c|c|}
\hline S.No. & \multicolumn{1}{|c|}{ Test description } & Results & Limits \\
\hline 1. & Combined Flakiness \& Elongation & $28 \%$ & $\leq 30$ \\
& Index & & \\
\hline 2. & Specific Gravity & & \\
& $20 \mathrm{~mm}$ & 2.669 & - \\
& $10 \mathrm{~mm}$ & 2.665 & - \\
& Stone Dust & 2.679 & - \\
& Lime & 2.800 & - \\
\hline 3. & Water Absorption & $1.2 \%$ & $\leq 2$ \\
\hline 4. & Aggregate Impact Value & $5 \%$ & $\leq 30$ \\
\hline 5. & Stripping Value & & $\leq 5$ \\
\hline
\end{tabular}




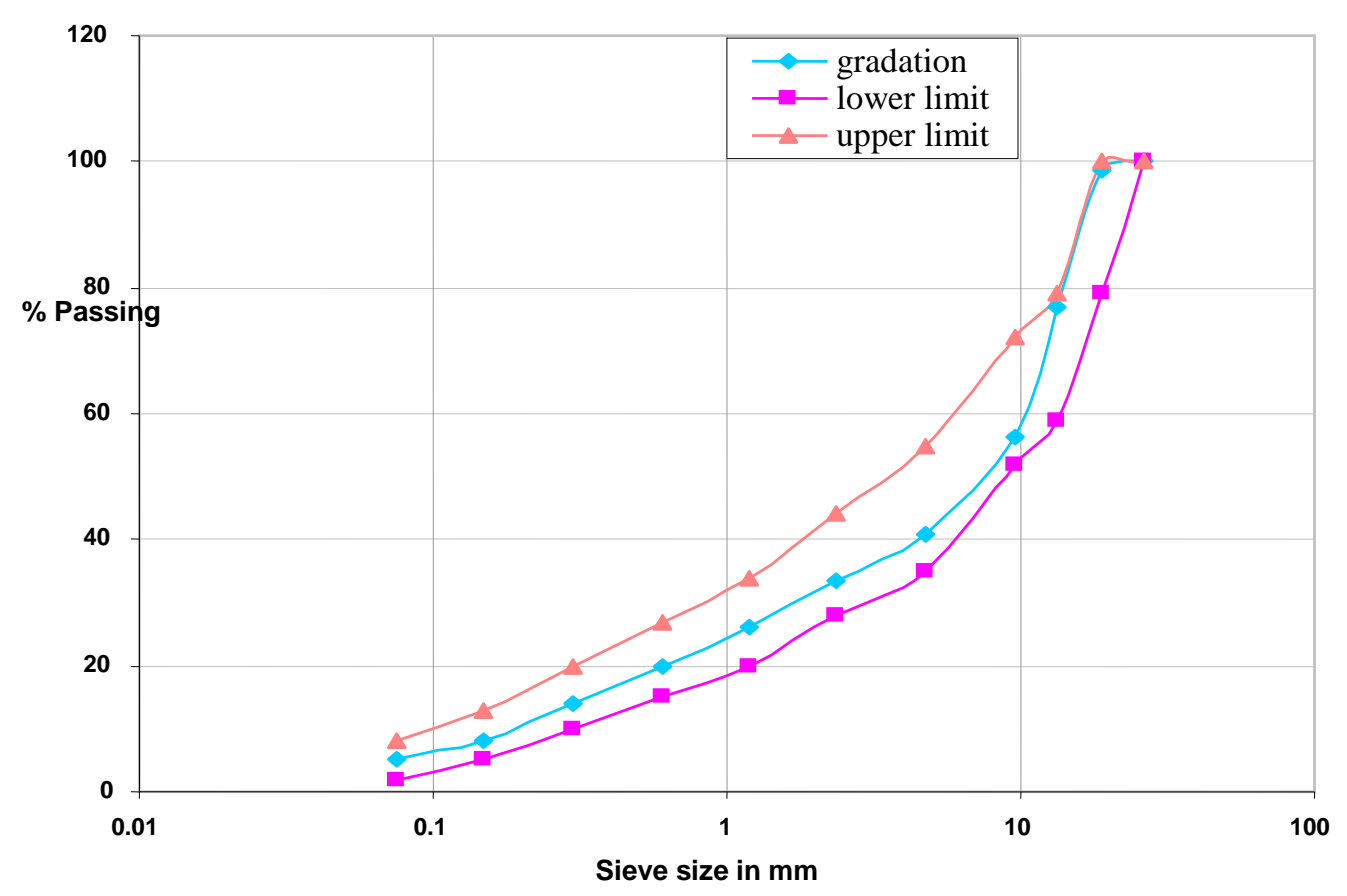

Figure 1. Aggregate gradation of asphalt concrete mix

\subsection{Asphalt Concrete Mix Design}

Marshall Method as per Asphalt Institute Manual (MS 2, 1997) of mix design was done for determination of optimum asphalt content (OAC) and found to be $5.3 \%$ by weight of aggregate. The properties of the Marshall design and limits for AC as per MoRTH specifications are given in Table 3.

Table 3. Asphalt concrete mix design values

\begin{tabular}{|c|l|l|l|}
\hline Sr. No. & \multicolumn{1}{|c|}{ Parameters } & Results & Specified Limit \\
\hline 1. & Stability $(\mathrm{kN})$ & 11.65 & 9 minimum \\
\hline 2. & Flow $(\mathrm{mm})$ & 3.1 & $2-4$ \\
\hline 3. & Density $(\mathrm{g} / \mathrm{cm} 3)$ & 2.362 & - \\
\hline 3. & Air Voids, \% & 5 & $3-6$ \\
\hline 4. & $\begin{array}{l}\text { Voids Filled with Asphalt (VFB), } \\
\%\end{array}$ & 72 & $65-75$ \\
\hline 5. & Retained Stability (\%) & 84 & 75 minimum \\
\hline
\end{tabular}

\subsection{Reinforcement of Asphalt Mix Using Glass Fiber and Polyester Fiber}

Marshall Mix design using glass fiber was carried out in the laboratory through the following steps. The four major steps used for modified mix design are briefly discussed here.

1. Materials (fiber) selection.

2. Mix procedure.

3. Selection of optimum glass fiber content to Binder content ratio (Fc/AC).

4. Various tests performed on optimum $\mathrm{Fc} / \mathrm{AC}$ ratio. 


\subsection{Material (Fiber) Selection}

The glass fiber and Polyester fiber which were selected for the present study has melting point much higher than required by the asphalt mix during mixing and lying. The test results of glass fiber and Polyester fiber properties are given in Table 4.

Table 4. Properties of glass and polyester fibers used

\begin{tabular}{|l|c|c|}
\hline Test & Glass Fiber & Polyester Fiber \\
\hline Color (visual) & White & White \\
\hline Shape & Rectangular & Circular \\
\hline Fiber width $(\mathrm{mm})$ & 1.0 & 0.002 \\
\hline Fiber Cut Length $(\mathrm{mm})$ & 10 & 8 \\
\hline Tensile Strength $(\mathrm{MPa})$ & 1400 & $9 \times 104$ \\
\hline Modulus of Elasticity $(\mathrm{MPa})$ & 70000 & $8 \times 106$ \\
\hline Melting Point $\left({ }^{\circ} \mathrm{C}\right)$ & $>300$ & $>250$ \\
\hline Specific Gravity $(\mathrm{g} / \mathrm{cm} 3)$ & 2.52 & 1.34 \\
\hline Moisture - $(\%)$ & $<0.20$ & $<0.5$ \\
\hline Loss on Ignition $-(\%)$ & $<0.25$ & $<0.5$ \\
\hline Non-Fibrous Material $-(\%)$ & $<1.00$ & $<2.5$ \\
\hline
\end{tabular}

\subsection{Mixing Fibers with Asphalt Mix}

As the glass and polyester fibers were not uniformly dispersing in the binder therefore experiment was performed to calculate the melting point of the fibers and after experimentations it was seen that the fibers had high melting point i.e. $>300{ }^{\circ} \mathrm{C}$ and $>250^{\circ} \mathrm{C}$ for glass and polyester fibers respectively. The mixing temperature of asphalt is around $150{ }^{\circ} \mathrm{C}-160{ }^{\circ} \mathrm{C}$ so the fibers were not blended with the binder but are added to the mix. An automatic mixer was used to mix the fibers for five minutes known as dry mixing.

\subsection{Selection of Optimum Fiber to Binder Ratio (Fc/AC)}

The volumetric analysis of various parameters in asphalt mix design at varying asphalt content and doses of fibers were performed to arrive at glass fiber/Polyester fiber to binder ratio as the same was adopted for finding out Optimum Binder Content (OBC). Marshall Samples were made using glass and polyesters fibers and also calculated for various tests for volumetric analysis. Air voids were kept around 5$5.5 \%$ with voids filled with asphalt in the range of $68-75 \%$. With glass fibers OBC was found to be $5.32 \%$ with glass fiber content of 0.15 percent and for polyester fiber, OBC was found to be $5.35 \%$ with fiber content of 0.20 percent.

\section{TEST RESULTS AND ANALYSIS}

A number of tests were done to characterize the mechanical properties of AC mixtures. The tests used in the study concerned resilient modulus, repeated load deformation, flexural beam fatigue, indirect tensile and skid resistance. Each of these tests is described in brief with test results of samples made with and without fibers. 


\subsection{Marshall Stability Test}

The Marshall Stability test was done as per ASTM D 1559 (1989) and AASHTO T245 (2008). Stability of an asphalt mix depends on internal friction and cohesion. Fibers provide better bonding in the mix. The test results of various mixes with and without fibers are given in Table 5. The retained Marshall stability as per MS 14 (Appendix H) is given in Table 6.

\subsection{Indirect Tensile Strength}

This test measures the splitting tensile strength of asphalt mixes. The indirect tensile strength (ITS) test which is tensile strain at failure, is more useful in predicting cracking potential. The test was done as per ASTM D 7369 (2011). The test results of various mixes with and without fibers are given in Table 5. The retained tensile strength (tensile strength ratio) as per AASHTO T 283 (2007) is also given in Table 6.

Table 5. Marshall Stability and ITS

\begin{tabular}{|l|l|l|c|}
\hline Tests & $\begin{array}{l}\text { Plain AC } \\
\text { mix }\end{array}$ & $\begin{array}{l}\text { AC Mix With } \\
\text { glass fibers }\end{array}$ & $\begin{array}{c}\text { With polyester } \\
\text { fiber }\end{array}$ \\
\hline Average Stability, KN & 11.60 & 12.85 & 13.10 \\
\hline ITS (MPa) & 89 & 111 & 108 \\
\hline
\end{tabular}

Table 6. Retained stability and tensile strength ratio

\begin{tabular}{|l|l|l|c|}
\hline Tests & $\begin{array}{l}\text { Plain AC } \\
\text { mix }\end{array}$ & $\begin{array}{l}\text { AC Mix With } \\
\text { glass fibers }\end{array}$ & $\begin{array}{l}\text { AC Mix With } \\
\text { polyester fiber }\end{array}$ \\
\hline Retained Stability, $\%$ & 84 & 89 & 84 \\
\hline Tensile strength ratio, $\%$ & 89 & 93 & 94 \\
\hline
\end{tabular}

\subsection{Diametrical Resilient Modulus}

The resilient modulus of a mixture is a relative measure of mixture stiffness. The test procedure used in this study was ASTM D 4123-82(1995). The test was performed by applying five haversine load pulses of $2000 \mathrm{~N}$ on one diametric axis and measuring the deformation on the perpendicular axis. Because of the non-destructive nature of resilient modulus testing, the same samples were tested after rotating through $90^{\circ}$ and the average of the two values was taken. Three samples were tested at each temperature. Testing was done at two temperatures $25^{\circ} \mathrm{C}$ and $35^{\circ} \mathrm{C}$. The test results are given in Table 7 . 
Table 7. Resilient modulus of asphalt concrete mixes

\begin{tabular}{|c|c|c|c|}
\hline \multirow[t]{2}{*}{ Parameter } & \multirow{2}{*}{$\begin{array}{l}\text { Plain } \\
\text { Mix }\end{array}$} & \multicolumn{2}{|c|}{ Mix Reinforced } \\
\hline & & $\begin{array}{l}\text { With Glass } \\
\text { Fiber }\end{array}$ & $\begin{array}{l}\text { With Polyester } \\
\text { Fiber }\end{array}$ \\
\hline Average Resilient Modulus at $25^{\circ} \mathrm{C}(\mathrm{MPa})$ & 3109 & 4287 & 4226 \\
\hline Average Resilient Modulus at $35^{\circ} \mathrm{C}(\mathrm{MPa})$ & 1077 & 1282 & 1446 \\
\hline
\end{tabular}

\subsection{Repeated Load Deformation}

Repeated load deformation tests (Hafeez Imran et.al 2011 \& Vos, K.B. 2002) are useful in comparing the rutting susceptibility of different mixtures. In Universal Testing Machine UTM-5P, strain test applies a repeated load of defined magnitude and cyclic duration to specimens. For the current study, a static conditioning stress and conditioning time was applied prior to commencement of actual test. Conditioning time and conditioning stress were kept $100 \mathrm{~s}$ and $10 \mathrm{KPa}$ respectively. In most procedures, the point at which tertiary flow begins is of greatest interest. In this study test was done using UTM-5P. The load pulses required to reach 25,000 micro strain $(2.5 \%)$ were used as an additional indicator, designated as the cycles to failure or $3600 \mathrm{~s}$ of loading whichever is earlier. Test results of accumulated strain on mix samples at $40^{\circ} \mathrm{C}$ and $60^{\circ} \mathrm{C}$ are shown in Table 8 . Test results indicated that accumulated creep strain in FMACM Mix is lower than plain asphalt mix. Fig 2 shows the pattern of creep stiffness and accumulated strain in repeated load test.

Table 8. Accumulated strain of asphalt concrete mix at $40^{\circ} \mathrm{C}$ and $60^{\circ} \mathrm{C}$

\begin{tabular}{|c|c|c|c|c|c|c|}
\hline Parameter & $\begin{array}{l}\text { Plain } \\
\mathrm{Mix} \text { at } \\
40^{\circ} \mathrm{C}\end{array}$ & $\begin{array}{l}\text { Plain } \\
\text { Mix } \\
\text { at } \\
60^{\circ} \mathrm{C}\end{array}$ & $\begin{array}{l}\text { AC With } \\
\text { Glass } \\
\text { Fiber at } \\
40^{\circ} \mathrm{C}\end{array}$ & $\begin{array}{l}\text { AC With } \\
\text { Glass } \\
\text { Fiber at } 60 \\
{ }^{\circ} \mathrm{C}\end{array}$ & $\begin{array}{l}\text { AC With } \\
\text { Polyester } \\
\text { Fiber at } \\
40^{\circ} \mathrm{C}\end{array}$ & $\begin{array}{l}\text { AC With } \\
\text { Polyester } \\
\text { Fiber at } \\
60^{\circ} \mathrm{C}\end{array}$ \\
\hline $\begin{array}{l}\text { Accumulated } \\
\text { Strain } \%\end{array}$ & 0.92 & 2.5 & 0.75 & 1.62 & 0.72 & 1.74 \\
\hline
\end{tabular}

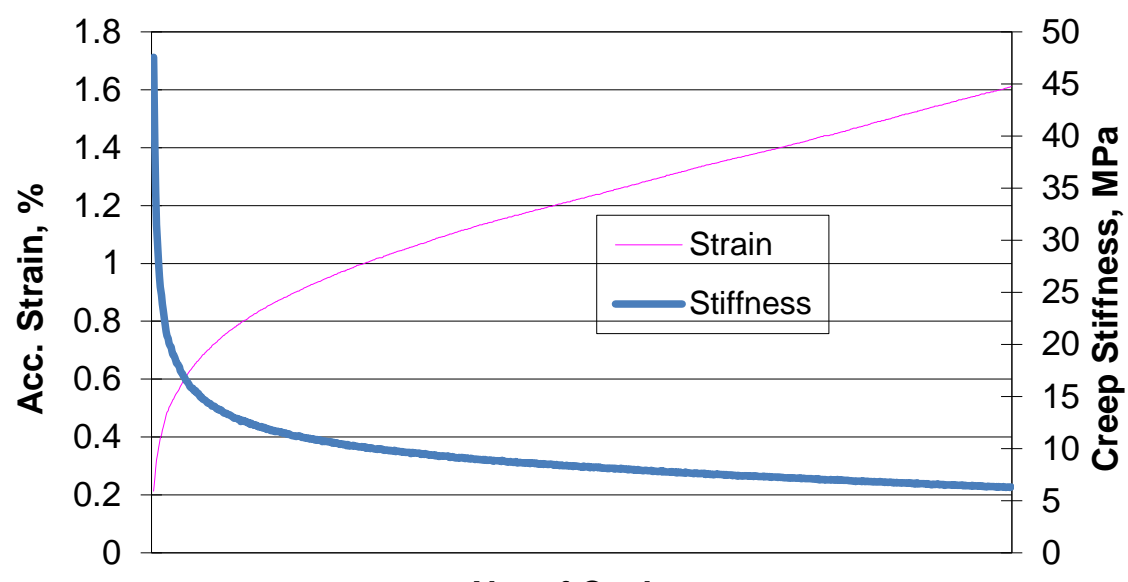

No. of Cycles

Figure 2. Strain vs. stiffness for creep test for mix with glass fiber at $60^{\circ} \mathrm{C}$. 


\subsection{Flexural Beam Fatigue Test}

The results from a beam fatigue test can be used to provide an estimation of the number of wheel loads that can be carried by a pavement before fatigue cracking appears. In this study, the fatigue properties of the FMACM and unmodified asphalt mixtures were measured and compared. Each of the asphalt mixtures used for the beam fatigue test was prepared using standard laboratory procedure. Beam fatigue samples were prepared and tested in accordance with ASTM D 7460 (2010) at $25^{\circ} \mathrm{C}$. Fatigue failure is defined as the point where $50 \%$ of the initial stiffness of the beam specimen remains and the number of cycles are known as fatigue life cycles. The test jig set-up for fatigue test is shown in Photo 1 . The test results for flexure stiffness of flexure beam fatigue test at constant strain mode for $300 \& 500$ micro-strains for plain AC mixes and FMACM and number of fatigue life cycles are shown in Table 9. FMACM has sustained higher number of cycles to reach level of $50 \%$ of initial stiffness compared to plain mix as shown in Figure 3.

Table 9. Comparisons for Initial Stiffness and Number of Fatigue Life Cycles of Mixes at $25^{\circ} \mathrm{C}$

\begin{tabular}{|l|c|c|l|l|l|l|c|}
\hline $\begin{array}{l}\text { TYPE } \\
\text { MIX }\end{array}$ & Plain AC & $\begin{array}{l}\text { AC mix } \\
\text { With } \\
\text { glass } \\
\text { fiber }\end{array}$ & $\begin{array}{l}\text { AC mix } \\
\text { With } \\
\text { Polyester } \\
\text { fiber }\end{array}$ & $\begin{array}{l}\text { Plain AC } \\
\text { Mix }\end{array}$ & $\begin{array}{c}\text { AC } \\
\text { With } \\
\text { fiber }\end{array}$ & $\begin{array}{r}\text { mix } \\
\text { glass }\end{array}$ & $\begin{array}{c}\text { AC mix } \\
\text { With } \\
\text { Polyester } \\
\text { fiber }\end{array}$ \\
\hline \multicolumn{2}{|c|}{ Initial Stiffness (MPa) } & \multicolumn{3}{|c|}{ Number of Fatigue Life Cycles } \\
\hline Micro & $300 \mu$ & 1265 & 1735 & $\begin{array}{l}1564 \\
1247\end{array}$ & $\begin{array}{l}15208 \\
8\end{array}$ & $\begin{array}{l}196642 \\
42560\end{array}$ & $\begin{array}{l}212860 \\
59762\end{array}$ \\
Strain & $500 \mu$ & 1089 & 1397 & & 41064 & & \\
\hline
\end{tabular}

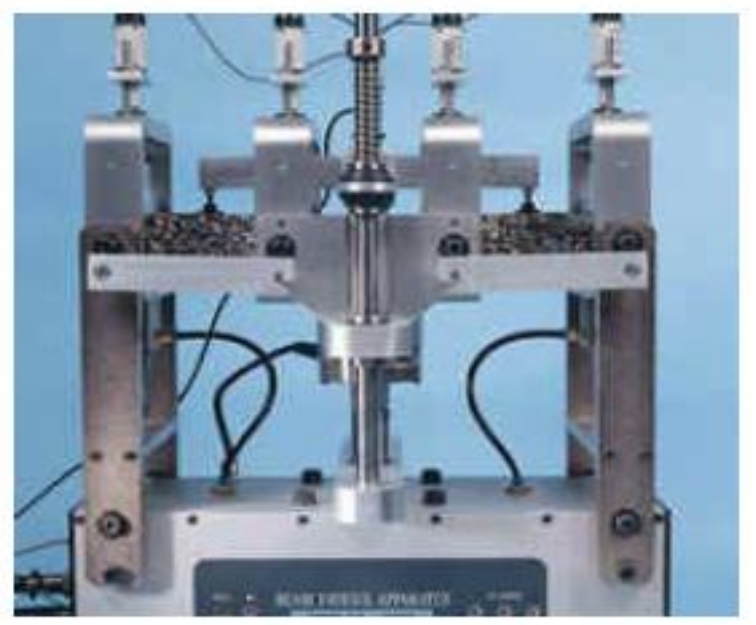

Photo 1. Flexure Beam Fatigue Test Jig 


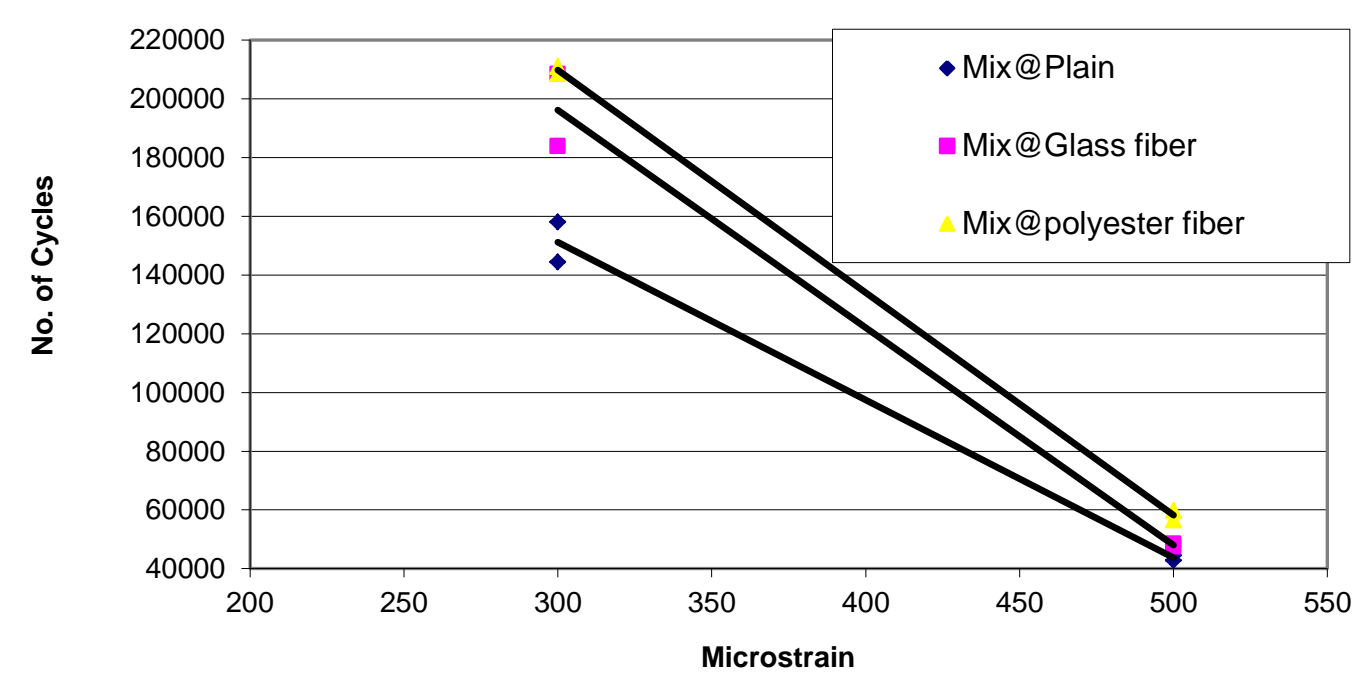

Figure-3: Fatigue life cycle of bituminous mixes

\subsection{Hamburg Wheel Tracking Test}

The Hamburg Wheel-Tracking Device (Sousa, J.B. et.al 1998 \& AASHTO T 324, 2011) measures the combined effects of rutting and moisture damage by rolling a steel wheel across the surface of an asphalt concrete slab that is immersed in hot water. The device was developed in the 1970's by Esso A.G. of Hamburg, Germany, based on a similar British device that had a rubber tire. The machine was originally called the Esso Wheel-Tracking Device. This test method covers the determination of rut depth of rectangular specimen (slab) of asphalt mix of size $300 \times 150 \times 75 \mathrm{~mm}$. Rutting in the specimen occurs due to repetitive action of wheel subjected to standard axle load. The contact area between wheel and specimen is about $5.45 \mathrm{~cm} 2$ giving a mean normal pressure $566 \mathrm{KPa}$. The depth of the impression being recorded at the midpoint of its length by means of a rut depth measuring device. The slabs were compacted with static compression machine to achieve compaction level of 5 to 6 percent air voids in the mix. Each sample is loaded at $50{ }^{\circ} \mathrm{C}$ for 20000 passes or until $20 \mathrm{~mm}$ depression whichever occurs earlier. The total rut depth at 20000 passes for plain AC mix and Fiber modified mix is given in Table 10 and the pattern of rutting is shown in Figure 4.

Table 10. Rutting behavior of various mixes at $50^{\circ} \mathrm{C}$

\begin{tabular}{|l|l|l|c|}
\hline Type of Mix & $\begin{array}{l}\text { Plain AC } \\
\text { mix }\end{array}$ & $\begin{array}{l}\text { AC mix with } \\
\text { glass fiber }\end{array}$ & $\begin{array}{c}\text { With polyester } \\
\text { fiber }\end{array}$ \\
\hline Total rut depth, $\mathrm{mm}$ & $14 \mathrm{~mm}$ & $12 \mathrm{~mm}$ & $11 \mathrm{~mm}$ \\
\hline
\end{tabular}




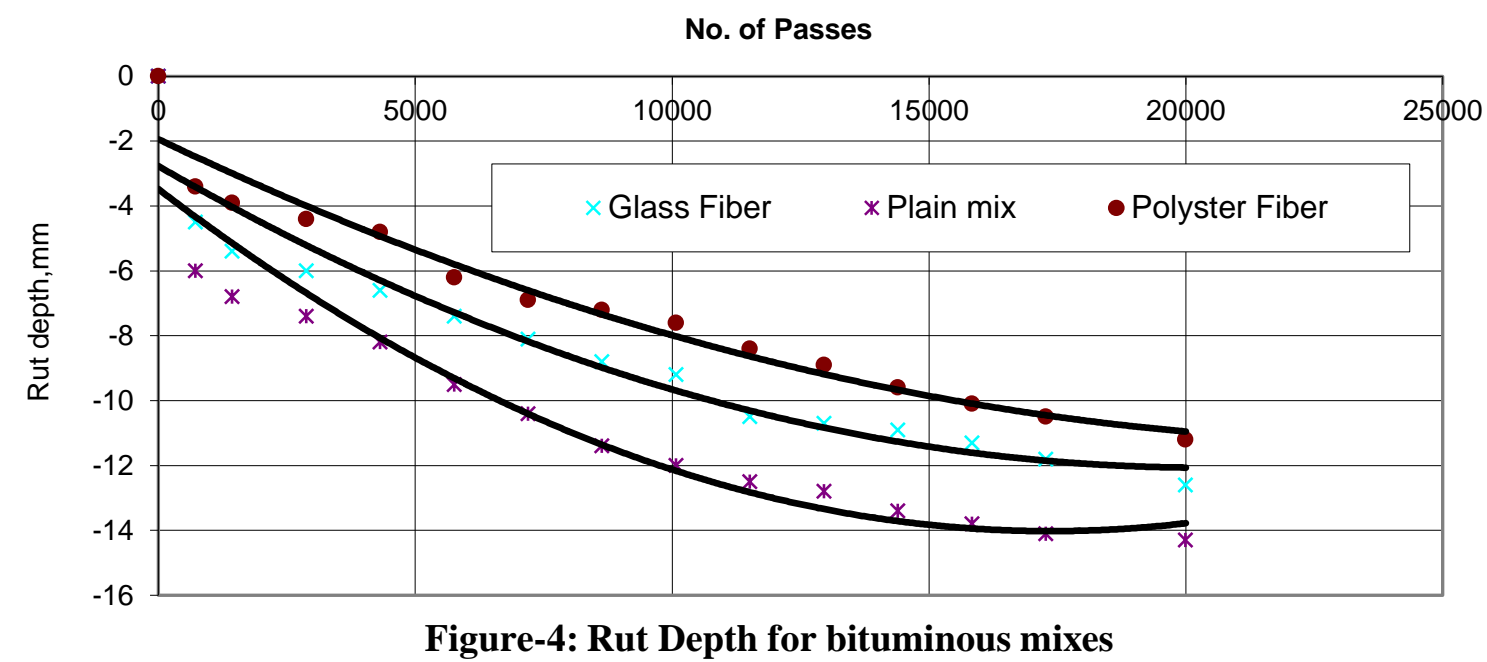

\subsection{Skid Resistance of Various Mixes}

Asphalt Slabs of sizes $350 \times 150 \times 75 \mathrm{~mm}$ made for rutting test were used to measure the skid resistance (at the centre and top of slab) of various mixes using British pendulum skid resistance tester as per ASTM E 303 (1993). During test it was found that skid resistance on asphalt surface improved which may indicate that the tensile reinforcement of fibers to aggregate and binder is strong enough as also shown in Table 11.

Table 11. Coefficient of skid resistance of various mixes

\begin{tabular}{|l|c|c|c|}
\hline $\begin{array}{l}\text { Coefficient of skid } \\
\text { resistance }\end{array}$ & $\begin{array}{l}\text { Plain AC } \\
\text { mix }\end{array}$ & $\begin{array}{l}\text { AC Mix With } \\
\text { glass fiber }\end{array}$ & $\begin{array}{l}\text { AC Mix With } \\
\text { polyester fiber }\end{array}$ \\
\hline Dry condition & 0.81 & 0.88 & 0.83 \\
\hline Wet condition & 0.72 & 0.80 & 0.76 \\
\hline
\end{tabular}

\section{DISCUSSIONS AND CONCLUSION}

- With the addition of glass fiber and polyester fiber in Asphalt concrete mix, the optimum binder content increased by $0.02 \%$ and $0.05 \%$ respectively. Test results indicate that fibers require slightly more bitumen for coating.

- With the addition of glass fiber and polyester fiber in Asphalt concrete mixes, the Marshall stability increases upto $10 \%$ and $13 \%$ respectively.

- With the addition of glass fiber and polyester fiber in Asphalt concrete mix, the indirect tensile strength increases upto $25 \%$ and $21 \%$ respectively, whereas tensile strength ratio also increased upto $5 \%$ for both type of Fibers, which indicates that cracking in Asphalt concrete mixes may be delayed with addition of fibers.

- With the addition of glass fiber and polyester fiber in Asphalt concrete mix, the average resilient modulus increases upto $38 \%$ and $36 \%$ respectively at 
temp of $25^{\circ} \mathrm{C}$ whereas the increase in resilient modulus is upto $19 \%$ and $34 \%$ respectively at temperature of $35^{\circ} \mathrm{C}$.

- FMACM have shown significantly less Accumulated creep strain i.e. $18 \%$ \& $22 \%$ less at $40^{\circ} \mathrm{C}$ and $35 \%$ \& $38 \%$ less at $60^{\circ} \mathrm{C}$ respectively for glass fiber and polyester fiber. Test results indicate the behavior of mix with polyester fiber changes with increase in temperature as the same is susceptible to less strain at $60^{\circ} \mathrm{C}$ compare to mix with glass fiber.

- FMACM have shown significant improvement $29 \%$ and $40 \%$ in Fatigue life cycles of the mix at $25^{\circ} \mathrm{C}$ at control strain mode at strain level of $300 \mu$ for glass fiber and polyester fiber respectively whereas improvement of $28 \%$ and $46 \%$ in Fatigue life cycles of the mix at $25^{\circ} \mathrm{C}$ at control strain mode at strain level of $500 \mu$ for glass fiber and polyester fiber respectively.

- FMACM are less susceptible to rutting, as test results indicated that at $50^{\circ} \mathrm{C}$, for 20000 passes, the total rut depth of FMACM is significantly less by $14 \%$ \& $21 \%$ for glass fiber and polyester fiber respectively. However test results indicate that polyester fiber has shown better performance in rutting test but not in Accumulated creep test at $60^{\circ} \mathrm{C}$.

- The ability of fiber to increase the tensile strength of Asphalt concrete mixtures at low temperatures have indicated higher modulus and fatigue life cycles. Rutting potential of FMACM at $60^{\circ} \mathrm{C}$ temperature also indicated better performance for hot climatic condition.

- Glass fiber modified mix has also shown improvement in the skid resistance by $8 \%$ and $11 \%$ in dry and wet conditions respectively on samples prepared and tested in laboratory whereas there is not much improvements in skid resistance observed in Polyester fiber modified mix. 


\section{REFERENCES}

AASHTO T 245, 2008 "Standard Method of Test for Resistance to Plastic Flow of Asphalt Mixtures Using Marshall Apparatus".

AASHTO T 283, 2007 "Standard Method of Test for Resistance of Compacted Asphalt Mixture to Moisture-Induced Damage".

AASHTO T 324, 2011 "Standard Method of Test for Hamburg Wheel-Track testing of Compacted Hot Mix Asphalt".

Abdelaziz Mahrez, et. Al 2005, "Fatigue and Deformation Properties of Glass Fiber Reinforced Asphalt Mixes", Journal of the Eastern Asia Society for Transportation Studies, Vol. 6, 2005 pp. 997 - 1007.

ASTM E 303-93, 2008 "Standard Test Method for measuring surface frictional properties using the British Pendulum tester".

ASTM D 7460, 2010 "Standard Test Method for determining Fatigue Failure of Compacted Asphalt Subjected to Repeated Flexure Bending”.

ASTM D 1559, 1989 "Standard Method of Test for Resistance to Plastic Flow of Asphalt Mixtures Using Marshall Apparatus".

ASTM D 73692011 "Standard test Method for determining the Resilient Modulus of Asphalt concrete Mixture by Indirect Tension Test".

Busching H.W. and J.D. Antrim 1968 "Fiber Reinforcement of Asphalt Mixtures." Journal of the Association of Asphalt Paving Technologists, Vol. 37, 1968 p 629-656.

Decoene, Y. 1990 "Contribution of cellulose fibers to the performance of porous asphalts", Transportation Research Record n 1265, 1990, p. 82-88.

Imran Hafeez \& Mumtaz Ahmed Kamal, 2011 "Repeated Load Permanent Deformation Behavior of Mixes With and Without Modified Bitumen", Mehran University Research Journal of Engineering \& Technology, Volume 30, No. 1, January, 2011.

IS: 1201 to 1220,1978 "Indian Standard Methods for Testing Tar and Asphalt", IS: 1201 to 1220, Bureau of Indian Standards.

IS: 2386, 1978 "Indian Standard Methods of Test for Aggregate for Concrete", IS: 2386, Bureau of Indian Standards.

Jiang, Yi; Rebecca S. McDaniel., 1993 "Application of Cracking and Seating and Use of Fibers to Control Reflection Cracking" Transportation Research Record n 1388, p150-159. 
Maurer, Dean A.; Gerald Malasheskie., 1989 "Field performance of fabrics and fibers to retard reflective cracking" Transportation Research Record No. 1248, 1989, p 1323.

"Mix Design Methods for Asphalt Concrete and other Hot Mix Types" 1997, The Asphalt Institute, Manual (MS-2), USA.

Praveen Kumar, et.al. 2009 "Investigation of Fiber Modified Asphalt Mixes", Journal of Transportation Research Board, Transportation Research Board of the National Academies, Vol. 2126, 2009 p 91-99.

Serfass, J.P.; J. Samanos. 1966 "Fiber-Modified Asphalt Concrete Characteristics", Applications and Behavior. Journal of the Association of Asphalt Paving Technologists, Vol. 65, 1966 p 193-230.

Simpson, et. al 1994, "Case study of modified asphalt mixtures: Somerset, Kentucky" Proceedings of the Third Materials Engineering Conference 804 Oct 1994, ASCE p 88-96.

Sousa J.B. et. al. 1998 "Bridged procedure to determine permanent Deformation in Asphalt Concrete Pavements" Transportation Research Record 1448, TRB, National Research Council, Washington DC, pp 25-33.

Specifications for Road and Bridge Works, Fourth Revision, 2001 "Physical Requirements of Aggregate for Asphalt Concrete", Ministry of Road Transport and Highways (2001), Indian Roads Congress, New Delhi, India.

Vos, K.B. et al. 2002 "Feed Back Controlled Repeated Uniaxial Loading Strain Test," Hardware Reference Manual, Universal Testing Machine (UTM-5P), Test No. 20, pp. 1-21, September, 2002. 